\title{
Instrumentação de ensino em geografia nos anos finais do ensino fundamental
}

\author{
Geography teaching instrumentation in the final years from the \\ elementary school
}

Tiago Fernandes Rufo'; Gilvan Charles Cerqueira Araújo"

\begin{abstract}
RESUMO
Este artigo tem por objetivo propor uma reflexão envolvendo a instrumentação de Ensino em Geografia com a Base Nacional Comum Curricular (BNCC). Por meio de uma conceituação a respeito da importância dos instrumentos de ensino e das estratégias didático-pedagógicas, apresenta-se uma análise individual dos Anos Finais do Ensino Fundamental, e de como a instrumentação de ensino em Geografia pode ser desenvolvida nesta etapa da Educação Básica. Por meio de uma revisão bibliográfica, o presente trabalho é dividido em duas partes de aprofundamento analítico e complementares. No primeiro momento, há a apresentação e delineamento conceitual sobre a instrumentação de ensino. Como segundo passo analítico, há as habilidades específicas da BNCC para cada um dos Anos Finais do Ensino Fundamental, de modo a identificar e propor metodologias de instrumentação de ensino nesta etapa da Educação Básica.
\end{abstract}

Palavras-chave: Currículo; Geografia Escolar; Instrumentação de Ensino em Geografia

\section{ABSTRACT}

This article has as goal to propose a reflection involving the instrumentation of Geography Teaching with the Brazilian Common National Curricular Base (BNCC). Through a conceptualization about the significance of teaching instruments and didactic-pedagogical strategies, we present an individual analysis of the phases from the final years of brazilian elementary school, and how the teaching instrumentation in geography can be developed in this stage of Basic Education. Through a bibliographic review, the present paper is divided into two parts of analytical and complementary study. In the first moment, there is the presentation and conceptual outline on the teaching instrumentation. As a second analytical step, there are specific skills from Brazilian's common curriculum basis guide for each of the Final Years from the Elementary Brazilian's Education in order to identify and propose teaching instrumentation methodologies in this stage of Basic Education.

Keywords: Curriculum; School Geography; Instrumentation in Geography

\section{INTRODUÇÃO}

Este artigo possui uma proposta de análise formada por dois temas principais. Num primeiro passo há o desenvolvimento do conceito de instrumentação de ensino

'Doutorando em Geografia pela UnB. Professor da Secretaria de Educação do Distrito Federal. tiago.rufo@hotmail.com ORCID: https://orcid.org/0000-0001-9168-8653

"Doutorado em Geografia pela Universidade Estadual Paulista Júlio de Mesquita Filho (2016). Professor da Secretaria de Educação do DF. gcca99@gmail.com ORCID: https://orcid.org/0000-0003-4238-0139 
de Geografia, e as possibilidades de construção de estratégias didático-pedagógicas para a Geografia Escolar. Num segundo momento do debate proposto, explora-se a questão de como a instrumentação de ensino de Geografia pode ser encontrada e problematizada, teórica e metodologicamente nas prescrições curriculares da Base Nacional Comum Curricular para o Ensino Fundamental em seus Anos Finais.

O trabalho é composto pela temática da construção curricular com seus diferentes elementos e atores do processo de ensino e aprendizagem. A escolha dos conteúdos e objetos de conhecimento, o direcionamento dos processos cognitivos de acordo com os objetivos de aprendizagem de cada fase das etapas e/ou modalidades da Educação Básica, a importância dos professores e gestores em sua formação inicial e continuada, a inserção dos conhecimentos prévios dos estudantes para a proposição e elaboração de estratégias didático-pedagógica, são alguns dos pontos que devem ser considerados no processo de construção de uma proposta curricular (ADURIZ-BRAVO, et. al., 2015; FISCHER, 2016).

A partir deste objetivo principal, o presente artigo desenvolve-se por meio de revisão bibliográfica concomitante a uma análise documental, com a utilização de autores de grandes áreas do ensino de Geografia, relacionados às especificidades da Geografia Escolar e, também, que teorizam e propõem formas de operacionalização prática e epistemológica da ideia de instrumentação de ensino e desenvolvimento de estratégias didático-pedagógicas para o ambiente escolar (CALLAI, 2005, 2010; KAERCHER, 2004; SURMACZ, LEME, 2015; PAZINI, 2005; MCGUIRE; TUCHANSKA, 2013; IPARRAGUIRRE, 2013).

O artigo é composto, desta forma, em dois momentos complementares entre si. De início, apresenta-se a conceituação e definição a respeito da instrumentação de ensino, de modo a subsidiar a análise pretendida em relação ao escopo a ser trabalhado no restante do artigo. Após este primeiro momento, investe-se na análise, ano a ano, de forma a propor caminhos para a instrumentação de ensino da Geografia Escolar da BNCC em relação aos Anos Finais do Ensino Fundamental, especialmente no que tange às habilidades específicas desta etapa da Educação Básica. 


\section{A INSTRUMENTAÇÃO E ENSINO E A GEOGRAFIA ESCOLAR: DIÁLOGOS COM A BNCC}

A instrumentação de ensino pode ser entendida como a produção de recursos didáticos e paradidáticos para o exercício da prática pedagógica. As ciências possuem seus aparatos teórico-conceituais e, nas escolas, tais aparatos teóricos precisam, muitas vezes, serem traduzidos e adaptados para os diferentes públicos da Educação Básica.

O saber escolar será sempre o esforço da ciência de se colocar para um público mais amplo, os estudantes e, neste sentido, a teoria e prática do pensamento científico encontra desafios para sua tradução à linguagem deste público em especial: as concepções contemporâneas de experiência científica não apenas reconhecem o caráter profundo e inevitavelmente teórico desta: "o nexo entre observação e manipulação, juntamente com o uso de equipamento tecnológico, [também] tem sido reconhecido" (McGUIRE; TUCHANSKA, 2013, p. 164).

A elaboração de recursos didáticos e instrumentos de ensino corrobora com o posicionamento de Mcguire e Tuchanska (2013), no sentido de que por eles ser possível uma chegada mais acessível dos saberes científicos ao ambiente escolar. Os recursos didáticos, chamados de material educativo para el proceso de enseñanza por Iparraguirre (2013) constitui-se de elementos como a manipulación, observación.

Herrero (2004) vai ao encontro das ideais de Iparraguirre (2013) quando disserta que "Desde una perspectiva didáctica podríamos decir que recurso es una forma de actuar, o más bien la capacidad de decidir sobre el tipo de estrategias que se van a utilizar em los procesos de enseñanza1;". E o autor continua sua argumentação definindo os recursos didáticos como característica inerente ao processo de ensino e aprendizagem:

[...] es, por tanto, una característica inherente a la capacidad de acción de las personas. Los médios didácticos podríamos definirlos como el instrumento del que nos servimos para la construcción del conocimiento; $y$, finalmente, los materiales didácticos serían los productos diseñados para ayudar em los procesos de aprendizaje. $^{2}$ (HERRERO, 2004, p. 3). 
Herrero (2004) ainda aprofunda o desenvolvimento do conceito de instrumento de ensino elevando-o à categorização de estratégia metodológica de aprendizagem. Observa-se que, neste sentido estratégico, o autor dialoga diretamente, por exemplo, com as diretrizes da nova base curricular nacional brasileira, em sua preconização do desenvolvimento de habilidades e competências para as aprendizagens, que vão acrescendo em complexidade e aprofundamento de acordo com os graus definidos pelas etapas e processos cognitivos das atividades realizadas no processo de aprendizagem:

En este sentido nos vamos a servir de los medios y materiales didácticos como un instrumento al servicio de las estrategias metodológicas. Esta idea ya se há apuntado al hablar de la utilización de recursos desde el punto de vista de la teoría interpretativa del currículum. Así, desde esta perspectiva cualquier médio formaría parte de los componentes metodológicos considerado em la categoría de material curricular, puesto que se convierte em herramienta de ayuda em la construcción del conocimiento. Los medios tecnológicos, sobre todo, como soportes de procesos de comunicación y de representación simbólica se conviertenen elementos mediadores de las situaciones de enseñanza y de los procesos de aprendizaje. $^{3}$ (HERRERO, 2004, p. 9).

Esta concepção dos processos de aprendizagem e cognição para a construção de conhecimento é colocado pelo autor como diferentes meios de desenvolvermos estratégias de ensino, sendo elas a técnica, a prática e estratégica, respectivamente correspondentes aos usos dos materiais, recursos e instrumentos didáticos em cada um dos casos, de forma reprodutiva, interpretativa ou crítica, como pode ser observado no quadro 01:

\section{Quadro 01: Paradigmas da Instrumentação de Ensino}

\begin{tabular}{|c|c|c|c|}
\hline Sobre o uso & Técnico & Prático & Estratégico \\
\hline Sobre a prática & $\begin{array}{c}\text { Papel reprodutor e } \\
\text { executor das orientações } \\
\text { que chegam desenhadas }\end{array}$ & $\begin{array}{c}\text { Projetos abertos que levam em } \\
\text { conta a realidade. Uso } \\
\text { recursivo da mídia. Reflexão } \\
\text { sobre a prática. }\end{array}$ & $\begin{array}{c}\text { Uso da mídia como } \\
\text { elementos de análise e } \\
\text { reflexão sobre a prática. }\end{array}$ \\
\hline Sobre os fins & $\begin{array}{c}\text { Alcance dos objetivos de } \\
\text { conduta }\end{array}$ & Importância dos processos & $\begin{array}{c}\text { Canais para modificar } \\
\text { códigos e eliminar } \\
\text { diferenças sociais e } \\
\text { culturais. }\end{array}$ \\
\hline Sobre a realidade & Escassa adequação & $\begin{array}{c}\text { Análise da realidade para dar } \\
\text { significado das situações }\end{array}$ & $\begin{array}{c}\text { Análise crítica para } \\
\text { transformar a realidade }\end{array}$ \\
\hline
\end{tabular}

Fonte: Organização e tradução dos autores, adaptado de Herrero (2004, p. 6). 
Percebe-se, neste caso específico de síntese dos processos cognitivos correlacionados por Herrero (2004), com as estratégias pedagógicas e as proposições de construção dos objetivos de conhecimento pelos estudantes previstos na BNCC, por meio das habilidades e competências, nas quais a criação e elaboração de hipóteses próprias abrem caminho para a transformação da realidade e do meio que se habita e significa.

Markuszewska et.al. (2018) faz uso da terminologia Creative Methods of Learning $(\mathrm{CML})$, que dialogam com as teorizações de Herrero (2004) e Iparraguirre (2013), em suas colocações sobre os recursos didáticos no ambiente escolar. Estes métodos criativos de ensino e aprendizagem somam-se e conectam-se diretamente com as estratégias pedagógicas e a instrumentação de ensino anteriormente apresentadas, e devem ser colocados em relevância para os novos desafios para uma educação holística, complexa e interdisciplinar para as novas gerações de estudantes:

[...] experiential learning is an abstraction that does not offer any exact methods and models to teaching pupils or students any better than before. The instructor is needed to select workable and reasonable teaching and learning methods in relation to the subject and the core of a study module. In practice, eligible learning outcomes and the content of the course are directing the selection of study methods. ${ }^{4}$ (MARKUSZEWSKA et. al., 2018, p. 38).

Estas considerações sobre o aprendizado experimental e práticas melhor direcionadas para as aprendizagens vão ao encontro dos argumentos tecidos por Eady e Lockyer (2013) e Mansilla e Jackson (2013), estes últimos em seu estudo intitulado: "Educating for Global Competence: Learning Redefined for na Interconnected World", que agregam-se, com as proposições de aprendizagens por habilidades e competências da BNCC. É neste sentido que, no resgate dos estudos e propostas educacionais de Dewey, Fischer (2016) propõe um investimento de criatividade e criação no ambiente escolar, por meio do desenvolvimento de habilidades por parte dos professores em sua prática didática:

To improve the research foundations of educational practice and policy requires building a stronger infrastructure to create better educational research. That research needs to be not only scientifi - cally sound but also connected with the way teaching and learning happen in important educational settings, such as schools, playing fi elds, television, and the Internet. Three changes that will 
contribute to a stronger infrastructure are (a) the creation of research schools to promote research that connects to practice and policy, (b) the establishment of useful databases on learning and development, and (c) the invention of a new class of educator who specializes in translating between research and practice and/or in engineering educational materials and activities based on research. ${ }^{5}$ (FISCHER, 2016, p. 12).

Os saberes científicos transpostos ao ambiente escolar devem, portanto, resgatar sua pulsão criativa e de elaboração de meios de intervir na realidade. É esta motivação por parte dos estudantes, em meio aos projetos e estratégias pedagógicas possibilitadas pela instrumentação de ensino, apontada por Pontuschka, Paganelli e Cacete (2009, p. 100):

É essencial a motivação do aluno para a elaboração de projeto próprio de ensino e aprendizagem em Geografia que envolva proposta teórico-pedagógica, demonstrando, portanto, domínio teórico-metodológico, bem como condição de realização prática e empírica. É necessário assinalar a importância de tomar como referência as práticas didático-pedagógicas e a realidade social da escola básica para os projetos de ensino e aprendizagem em Geografia, buscando alternativas para uma ação eficaz.

A busca, por parte do professor, deve se pautar, desta maneira, na motivação do estudante, propondo meios pelos quais o conhecimento escolar possa ser resignificado para o seu mundo cotidiano, diário. A senescência dos conteúdos, por meio das estratégias pedagógicas da instrumentação de ensino propostas pelos autores supracitados pode ser superada diariamente por meio desta visão perante a prática didática escolar:

Assim, além de dominar conteúdos, é importante que o professor desenvolva a capacidade de utilizá-los como instrumentos para desvendar e compreender a realidade do mundo, dando sentido e significado à aprendizagem. À medida que os conteúdos deixam de ser fins em si mesmos e passam a ser meios para a interação com a realidade, fornecem ao aluno os instrumentos para que possa construir uma visão articulada, organizada e crítica do mundo. (PONTUSCHKA; PAGANELLI; CACETE,2009, p. 97).

Nas competências específicas para as ciências humanas da BNCC, nas quais a Geografia está inclusa, observa-se a defesa da utilização dos recursos, materiais, meios e recursos didáticos disponíveis para a elaboração de estratégias pedagógicas no ambiente escolar:

7. Utilizar as linguagens cartográfica, gráfica e iconográfica e diferentes gêneros textuais e tecnologias digitais de informação e comunicação no desenvolvimento 
do raciocínio espaço-temporal relacionado a localização, distância, direção, duração, simultaneidade, sucessão, ritmo e conexão. (BRASIL, 2018, p. 355).

Esse horizonte visualizado para se chegar ao uso significativo destas estratégias são os processos cognitivos dos estudantes, compreende-se, portanto, o porquê da BNCC elencar os princípios do raciocínio geográfico como principal, por meio do qual, os professores de Geografia, neste caso tanto do Ensino Fundamental como no Ensino Médio, podem encontrar os caminhos para um processo de ensino e aprendizagem realmente significativo aos seus estudantes.

No quadro 2 observa-se os princípios do raciocínio geográfico:

\section{Quadro 2: Princípios do Raciocínio Geográfico}

\begin{tabular}{|c|c|}
\hline Princípio & Descrição \\
\hline Analogia & $\begin{array}{l}\text { Um fenômeno geográfico sempre é comparável a outros. A identificação das } \\
\text { semelhanças entre fenômenos geográficos é o início da compreensão da } \\
\text { unidade terrestre. }\end{array}$ \\
\hline Conexão & $\begin{array}{l}\text { Um fenômeno geográfico nunca acontece isoladamente, mas sempre em } \\
\text { interação com outros fenômenos próximos ou distantes. }\end{array}$ \\
\hline Diferenciação & $\begin{array}{l}\text { É a variação dos fenômenos de interesse da geografia pela superfície } \\
\text { terrestre (por exemplo, o clima), resultando na diferença entre áreas. }\end{array}$ \\
\hline Distribuição & Exprime como os objetos se repartem pelo espaço. \\
\hline Extensão & $\begin{array}{l}\text { Espaço finito e contínuo delimitado pela ocorrência do fenômeno } \\
\text { geográfico. }\end{array}$ \\
\hline Localização & $\begin{array}{l}\text { Posição particular de um objeto na superfície terrestre. A localização pode } \\
\text { ser absoluta (definida por um sistema de coordenadas geográficas) ou } \\
\text { relativa (expressa por meio de relações espaciais topológicas ou por } \\
\text { interações espaciais). }\end{array}$ \\
\hline Ordem & $\begin{array}{l}\text { Ordem ou arranjo espacial é o princípio geográfico de maior complexidade. } \\
\text { Refere-se ao modo de estruturação do espaço de acordo com as regras da } \\
\text { própria sociedade que o produziu. }\end{array}$ \\
\hline
\end{tabular}

Fonte: BNCC (BRASIL, 2018, p. 358).

Tais princípios da aprendizagem geográfica podem ser correlacionados com a leitura de mundo proposta por diferentes teóricos da Geografia Escolar. Para Callai (2005, p. 221):

[...] pensar uma Educação Geográfica significa superar as aprendizagens repetitivas e arbitrárias e passar a adotar práticas de ensino que invistam nas habilidades: análises, interpretações e aplicações em situações práticas; trabalhar a cartografia como metodologia para a construção do conhecimento geográfico. 
Ao se pensar na composição dos elementos das estratégias pedagógicas, cruzando-as com o raciocínio geográfico, observa-se que a correlação é não só imediata, como necessária, em se tratando em formas significativas de se levar o saber científico geográfico para a sala de aula, conforme ressalta a autora:

Assim, toda a aprendizagem da geografia na educação básica, entendida como um processo de construção da espacialidade que corresponde a orientar-se, deslocarse no espaço, pode ser associada aos seguintes objetivos:

1) Capacitar para a aplicação dos saberes geográficos nos trabalhos relativos a outras competências e, em particular, capacitar para a utilização de mapas e métodos de trabalho de campo.

2) Aumentar o conhecimento e a compreensão dos espaços nos contextos locais, regionais, nacionais, internacionais e mundiais e, em particular:

- conhecimento do espaço territorial;

- compreensão dos traços característicos que dão a um lugar a sua identidade;

- compreensão das semelhanças e diferenças entre os lugares;

- compreensão das relações entre diferentes temas e problemas de localizações particulares;

- compreensão dos domínios que caracterizam o meio físico e a maneira como os lugares foram sendo organizados socialmente;

- compreensão da utilização e do mau uso dos recursos naturais. (CALLAI, 2005, p. 211).

Diferentes autores(as) e estudos de Educação Geográfica e Geografia Escolar alinham-se, desta maneira, ao uso da instrumentação de ensino para a potencialização da prática didática no ambiente escolar, tais como Perez (2005), Guimarães e Odelfa (2014), Vlach (2003), Cavalcanti (2010), Callai (2010).

Vlach (2003) reforça, deste modo, o posicionamento que a utilização destes recursos, materiais, estratégias e instrumentos só tem a fortalecer a prática pedagógica da Geografia Escolar: 
sociais. Essa integração dinâmica não produz nem organiza um mundo homogeneizado; nem nos permite caracterizar o mundo como uma totalidade. Assim, diferentes recursos devem ser utilizados na aula de geografia, e os professores devem lutar para que os alunos tenham acesso às diversas fontes do conhecimento, de dados e informações, inclusive via internet, tendo em vista o saber. (VLACH, 2003, p. 10).

Com o desenvolvimento apresentado até este momento, outros pontos de apoio para a instrumentação de ensino devem ser considerados, como, por exemplo: o papel das Tecnologias de Informação e Comunicação (TICs) no processo de ensino e aprendizagem (com vistas a um aprofundamento crítico a respeito das propostas da Educação 4.0); A formação inicial e continuada dos professores, de modo a buscar o seu aperfeiçoamento no que diz respeito ao desenvolvimento da instrumentação de ensino e estratégias pedagógicas para as novas gerações de estudantes do século $\mathrm{XXI}$; A condução reflexiva das proposições didático-pedagógicas, consonante aos desafios levantados anteriormente sobre a instrumentação de ensino, ao que se é proposta como referência de produção, circulação, distribuição, acessibilidade e qualidade dos materiais didáticos a serem utilizados no ambiente escolar; conexão direta dos processos avaliativos por meio da ressignificação das aprendizagens pela instrumentação de ensino; a inserção da Educação Especial e Inclusiva no desenvolvimento das estratégias pedagógicas criativas e instrumentos de ensino; etc.

Neste momento é importante que se realize o direcionamento do debate envolvendo os elementos epistemológicos e teóricos da Geografia Escolar e ensino da Geografia presentes na BNCC para o Ensino Fundamental com os anos desta etapa da Educação Básica. A reflexão proposta, portanto, é de trazer um aprofundamento analítico da instrumentação de ensino e das estratégias pedagógicas para cada um destes anos, tendo como referência as prerrogativas curriculares da Geografia para o Ensino Fundamental da BNCC.

\section{A INSTRUMENTAÇÃO DO ENSINO DE GEOGRAFIA NOS ANOS FINAIS DE}

\section{ACORDO COM A BNCC}

Nas orientações da BNCC para o $6^{\circ}$ ano, em relação ao que deve ser ensinado em Geografia, observa-se que os objetos de conhecimento intitulados: "Relações 
entre os componentes físico-naturais", "Fenômenos naturais e sociais representados de diferentes maneiras" e "Biodiversidade e ciclo hidrológico" (BRASIL, 2018, p.383) possuem uma conotação mais atrelada à Geografia Física e com a cartografia. E ressalta-se a importância da dialogia entre a instrumentação de ensino, bem como a busca e elaboração de recursos didáticos para as fases elementares da Educação Básica, como é o caso da Geografia (EADY, LOCKYER, 2013; HERRERO, 2004).

Tradicionalmente, os parâmetros curriculares dos $6^{\circ}$ anos possuem engajamento maior com a Geografia Física e com a cartografia. Dessa forma, deve-se evitar a todo custo a imposição de dualismos ao conhecimento geográfico, algo que segundo Kaercher (2014) empobrece e simplifica a realidade dos assuntos e fenômenos abordados pelo campo geográfico. Conforme Vlach (2003):

Nossas aulas, principalmente nos ensinos fundamental e médio, devem, pois,
propor atividades para que os alunos possam entender, em primeiro lugar, que
nosso mundo é natural e social. As especificidades da natureza e da sociedade
devem merecer uma atenção redobrada, tendo em vista evitar-se a
homogeneização do mundo. (VLACH, 2003, p. 10).

Entretanto, a BNCC traz elementos claros que apontam para análise dos fenômenos geográficos na interface entre a Geografia Física e a Geografia Humana, dois campos imbricados e totalmente complementares, como por exemplo, quando indica o estudo dos movimentos do planeta Terra associados às dinâmicas e padrões climáticos, mas ao final também destaca o estudo dos impactos das atividades humanas sobre as dinâmicas climáticas, com ênfase nas ilhas de calor. Nesse aspecto, como aponta Kaercher (2004), a utilização das categorias da Geografia torna-se de fundamental importância para o estabelecimento das conexões e complementaridades entre os assuntos.

Há a valorização da paisagem e do lugar como categorias analíticas da Geografia. Nesse aspecto, um dos fios condutores do ensino de Geografia no $6^{\circ}$ ano é o de evidenciar as transformações das paisagens naturais em paisagens antrópicas/culturais e apresentar as consequências e problemáticas da interação sociedade-natureza. Entretanto, segundo Puntel (2007), deve-se evitar tratar os dois 
tipos de paisagens como elementos isolados e antagônicos, e sim como complementares e imbricados.

Também, nesta seção da BNCC, há o apontamento de três processos/fenômenos que desencadearam profundas transformações nas paisagens naturais: as atividades agropecuárias, a industrialização e a explosão do surgimento das cidades. Uma das grandes necessidades e que ainda pouco figuram no ensino de Geografia está na relação das categorias analíticas com os temas trabalhados em sala de aula. Dentre as categorias da Geografia, a consideração da paisagem revela-se essencial, pois possui grande importância na interpretação e compreensão de processos e fenômenos geográficos em diferentes momentos históricos. Em acréscimo a estas considerações, Puntel (2007) ressalta que a paisagem está atrelada ao lugar, outra categoria analítica da Geografia e que permite o estabelecimento de conexões do que é estudado com os aspectos ligados ao cotidiano do aluno.

Para Kaercher (2004), o ensino de Geografia deve fazer parte do cotidiano do aluno, sobretudo através de perguntas e espantos. Portanto, o professor deve objetivar tirar o aluno de sua zona de conforto e instigar a conexão de ideais, processos e fenômenos.

Entretanto, é importante ressaltar os desafios em torno dessa necessidade, tendo em vista a variedade de atrativos que os alunos têm acesso nos dias atuais, como por exemplo, as tecnologias, como os celulares e smatphones com conexão à internet. Assim, um aluno pode através de apenas um clique buscar o que realmente Ihe interessa em questão de segundos. Nesse caso, cabe aos profissionais da educação transformar esses desafios em oportunidades e ferramentas de aprendizagem do processo de ensino aprendizagem, com as muitas das tecnologias de informação e comunicação digitais utilizadas contemporaneamente.

Dentre as habilidades previstas para os $6^{\circ}$ anos, destacam-se as relacionadas à categoria paisagem: "Comparar modificações das paisagens nos lugares de vivência e os usos desses lugares em diferentes tempos" e "Analisar modificações de paisagens por diferentes tipos de sociedade, com destaque para os povos originários" (BRASIL, 2018, p.383). 
Puntel (2007) aponta para a necessidade de trabalhar a paisagem em sala de aula de forma que o aluno a entenda como integrante da sua realidade e de sua história, sendo capaz de identificar as transformações impostas pela sociedade, assim como as objetivações e intencionalidades. Sendo assim, o autor chama a atenção para o erro comum de abordar a paisagem apenas pelo caráter descritivo em detrimento das suas características dinâmicas.

A partir disso, evidencia-se que um dos caminhos possíveis de tratar a categoria paisagem é o de elaborar atividades complementares em torno da realidade local dos alunos, tendo como objetivo a identificação das características e transformações da paisagem local, seja ela urbana ou rural.

Os objetos de conhecimento relacionados às representações cartográficas evidenciam a necessidade de utilização de diferentes tecnologias e recursos disponíveis, como a Internet, ferramentas ligadas ao Sistema de Informação Geográfica (SIG) e de geoprocessamento, mapas digitais e interativos, entre outros aspectos. Para Pazini (2005), os SIG's são importantes ferramentas que possibilitam análises e correlações, além de permitirem maior visualização das transformações socioespaciais ao longo do tempo.

Segundo Vlach (2003):

Assim, diferentes recursos devem ser utilizados na aula de geografia, e os professores devem lutar para que os alunos tenham acesso às diversas fontes do conhecimento, de dados e informações, inclusive via internet, tendo em vista o saber. A utilização adequada dos mais sofisticados recursos tecnológicos não elimina o professor da sala de aula, mas valoriza o seu papel como aquele que é o responsável pelo trabalho pedagógico, na qualidade de mediador entre os alunos e o saber. (VLACH, 2003, p.10).

Dessa forma, como destacam Herrero (2004) e Ipaguirre (2013), a diversificação e o uso dos materiais didáticos, como por exemplo, a partir de meios tecnológicos, são importantes aliados e suportes de comunicação no processo de ensino e aprendizagem.

Portanto, o professor deverá se esforçar para qualificar e diversificar o ensino de Geografia através de formas criativas e dinâmicas de aprendizagem, com o intuito de motivar o aluno na construção dos raciocínios geográficos (SURMACZ; LEME, 
2015). Para Kaercher (2004), a cartografia, tão sempre associada e às vezes confundida como único caminho da Geografia, ainda é um recurso subutilizado em sala de aula.

O caráter da ludicidade é dos importantes aliados para tratar das atividades direcionadas aos alunos de $6^{\circ}$ ano. Entretanto, deve-se evitar o erro de repetição demasiada de um só tipo de recurso em sala de aula, o que pode tornar a aula enfadonha e cansativa para os alunos. Para Surmacz e Leme (2015), os conhecimentos geográficos devem ter significado para a vida do aluno.

Segundo Pazini (2005), com o advento do mundo globalizado, as imagens têm ganhado grande notoriedade e fazem parte do cotidiano e uma das importantes formas de comunicação. Os avanços tecnológicos e o acesso a produtos e recursos tecnológicos, como computadores, celulares e a Internet possibilitaram o contato com representações cartográficas com avançados graus de interatividade.

Dessa forma, a Geografia, como ciência que se preocupa com o espaço geográfico, deve nortear-se no ensino com apoio da cartografia e possibilitar a formação de estudantes com capacidade de leitura e interpretação de mapas e demais representações cartográficas. Nesse caso, a cartografia assume importante papel na promoção do ensino de Geografia ancorado no objetivo de entendimento, análise, interpretação e transformaçãodo espaço.

Silva e Muniz (2012) sublinham a importância dos materiais cartográficos e gráficos no ensino de Geografia, com potencial de ampliação da compreensão das dinâmicas espaciais e do contexto vivenciado pelos alunos. Nesse aspecto, as autoras defendem o uso de maquetes como ferramenta de representação cartográfica de caráter tridimensional, o que amplia a percepção espacial do aluno.

Como complementação ao uso de maquetes, o professor tem a oportunidade de aliar essa ferramenta de aprendizagem com a utilização de materiais recicláveis e o aprofundamento em questões atreladas aos conceitos de meio ambiente e sustentabilidade.

Para $07^{\circ}$ ano dos Anos Finais, na BNCC de Geografia, observa-se que a compressão da formação e configuração territorial brasileira é um dos pontos centrais do ensino de Geografia. Portanto, a categoria território deve guiar o ensino dos 
processos e eventos que levaram a formação do atual quadro socioeconômico, ambiental e econômico brasileiro.

Nesse caso, ressaltam-se as ideias de Cavalcanti (2011), que defende a necessidade de construção de conceitos que levem o aluno a adquirir possibilidades de entendimento do contexto e realidade espacial que ele está inserido por meio da instrumentação de ensino e desenvolvimento de estratégias didático-pedagógicas, além de estimular a identificação das contradições por meio da consideração e análise da forma/conteúdo e historicidade.

Dessa forma, o enfoque histórico deve ser valorizado com vistas ao entendimento das bases territoriais, sociais e econômicas que contribuíram para formação do território brasileiro. Nesse aspecto, torna-se importante evitar cair no erro de apresentar os processos apenas de forma descritiva, buscando variadas ferramentas metodológicas que estimulem o entendimento por parte do aluno. Para Cavalcanti (2011),

Compreendendo seu lugar e os territórios formados em suas proximidades, como uma espacialidade, o aluno terá uma convicção de que aprender elementos do espaço é importante para compreender o mundo, na medida em que ele é uma dimensão constitutiva da realidade, e estará, com isso, mais motivado para estabelecer com os conteúdos apresentados uma relação de cognição, colocandose como sujeito de conhecimento (CAVALCANTI, 2011, p.201).

A construção de raciocínios geográficos é um dos pontos fundamentais do ensino de Geografia, especialmente no caso brasileiro, onde há uma grande lacuna na formação da cidadania plena e de uma sociedade democrática. Para Fischer (2016), o fomento em direção ao aperfeiçoamento dos processos cognitivos no processo de ensino e aprendizagem é um dos caminhos mais profícuos a ser explorado nesta direção na qual se encontram os princípios do raciocínio geográfico. Nesse caso, é através da construção dos raciocínios geográficos que há a compreensão das principais problemáticas evidenciadas tanto no contexto local e como no global (VLACH, 2007). 
De acordo com Vlach (2007), deve-se entender que o território e a sociedade brasileira historicamente foram construídos à base da violência, autoritarismo e sob o viés escravista, resultantes do processo de colonização pautado na exploração.

Nesse caso, para desenvolvimento das habilidades, tais como: "Selecionar argumentos que reconheçam as territorialidades indígenas, de remanescentes de quilombolas, de povos das florestas e do cerrado, de ribeirinhos e caiçaras, entre outros grupos sociais do campo e da cidade, como direitos legais dessas comunidades", "Características da população brasileira" e "Analisar a distribuição territorial da população brasileira, considerando a diversidade étnico-cultural (indígena, africana, europeia e asiática), assim como aspectos de renda, gênero e idade nas regiões brasileiras" (BRASIL, 2018, p.385), o professor deverá guiar-se pelas contradições e os traços do processo de ocupação e formação territorial brasileiro, onde as comunidades ditas mais frágeis sofreram severos processos de violência, desterritorialização e exclusão.

Nesta fase dos Anos Finais em Geografia da BNCC, observa-se a previsão, também, do estudo sobre as questões demográficas recentes presentes na sociedade brasileira. Isso é observado na seguinte habilidade listada: "Analisar a distribuição territorial da população brasileira, considerando a diversidade étnico-cultural (indígena, africana, europeia e asiática), assim como aspectos de renda, gênero e idade nas regiões brasileiras" (BRASIL, 2018, p.385).

O ensino das questões demográficas pode ser pautado na realidade do aluno, pois, segundo Surmacz e Leme (2015), conhecer o público que tem contato é dos pontos essenciais para alavancar a qualidade do processo de ensino e aprendizagem.

Nesse sentido, atividades que investiguem a origem dos familiares dos alunos, assim como suas heranças históricas, memórias e vivências são vitais para iniciar o estudo das características atuais de distribuição e composição da população brasileira.

O teórico argentino Aduriz-Bravo et. al. (2015), em entrevista sobre a importância da utilização de recursos didáticos e instrumento para o ensino das ciências na escola considera que: 
Una ciencia escolar significativa, basada en modelos, que interviene de manera transformadora, que es mirada críticamente com el auxilio de la epistemología y la historia de la ciencia, y que resulta fundamental para tomar decisiones informadas em la vida cotidiana. (ADURIZ-BRAVO et. al. 2015, p. s/n).

Dentre os objetos de conhecimento e habilidades, está o de interpretar mapas temáticos referentes aos contextos econômicos e históricos e associados às regionalizações do território brasileiro. Além disso, prevê a análise e interpretação de diferentes tipos de gráficos, tendo como plano de fundo as regiões brasileiras. Nesse caso, o estudo das questões regionais é um dos pontos fundamentais do ensino de Geografia do $7^{\circ}$ ano.

O professor deverá então objetivar que o aluno entenda o caráter das desigualdades e similaridades socioeconômicas, históricas e físicas entre as regiões brasileiras. Para isso, é importante permitir ao aluno o conhecimento sobre as diferentes maneiras de regionalizar o território brasileiro, tais como a divisão regional promovida pelo Instituto Brasileiro de Geografia e Estatística (IBGE), a divisão proposta por Santos e Silveira (2010) baseada no meio técnico-científico e informacional e a divisão regional de Geiger (1969) por meio dos complexos geoeconômicos.

Assim sendo, o professor deve proporcionar ao aluno o entendimento de variadas formas de regionalizar o território brasileiro, para melhor compreender as suas diferentes variações de integração. Dessa forma, pode-se optar por uma das divisões regionais para dar andamento aos conteúdos, como a de Geiger (1969), com a utilização de interfaces e comparações entre as outras formas de regionalização. 0 aluno deve entender que o ato de regionalizar envolve um amplo aspecto de critérios e questões. Para isso, o professor pode optar por iniciar o conteúdo com a realização de pequenas regionalizações, elaborada pelos alunos, baseada em critérios e com a utilização do território local, como uma cidade, com o intuito do aluno identificar setores ou bairros com características singulares dentro do perímetro urbano.

Um dos pontos destacados é a produção dos mapas temáticos. A cartografia, portanto, deve ser um dos fios condutores para o entendimento das diferenças regionais no Brasil. Dessa forma, esse campo do conhecimento geográfico não deve 
ser abandonado e taxado como assunto de $6^{\circ}$ ano. Ao contrário disso, $07^{\circ}$ ano é o momento de intensificação da aplicação dos conhecimentos cartográficos, sendo os mesmos um dos principais aliados didático-pedagógicos no processo de ensino e aprendizagem nesta fase do Ensino Fundamental II.

Pazini (2005) defende o uso da cartografia como meio para o desenvolvimento ao que denomina de esquemas mentais responsáveis pela promoção da aprendizagem e maior autonomia na produção de conhecimento. Na seguinte passagem, Guimarães e Odelfa (2014) reforçam a potencialidade da cartografia no ensino de Geografia:

\begin{abstract}
Uma boa opção para que isso ocorra é utilizar o mapa, que é fonte riquíssima de informações de uma dada área. Ao levar em consideração a realidade vivida dos alunos, que pode ser o município, o estado ou o país, o mapa pode proporcionar o reconhecimento de informações sobre o seu cotidiano, que antes seriam desprezadas ou consideradas distantes da sua realidade (GUIMARÃES; ODELFA, 2014, p.72).
\end{abstract}

Nesse caso, os mapas temáticos possuem importante papel nas análises das dinâmicas socioespaciais e podem possibilitar maior atratividade aos alunos. Conforme Silva e Muniz (2012), a linguagem cartográfica permite ao aluno o entendimento e representação da sua realidade.

No $7^{\circ}$ ano, também há a previsão no campo "Biodiversidade brasileira" das habilidades de "Caracterizar dinâmicas dos componentes físico-naturais no território nacional, bem como sua distribuição e biodiversidade (Florestas Tropicais, Cerrados, Caatingas, Campos Sulinos e Matas de Araucária)" e "Comparar unidades de conservação existentes no Município de residência e em outras localidades brasileiras, com base na organização do Sistema Nacional de Unidades de Conservação (SNUC)" (BRASIL, 2018, p.385).

Uma das necessidades no estudo das habilidades citadas anteriormente está o de evitar o caráter tradicional do ensino das questões físico-territoriais brasileiras, tradicionalmente baseadas na descrição, como no estudo das diferentes formações vegetais presentes no país. Dessa forma, o professor deve propiciar ao aluno o 
contato com diferentes imagens, figuras, vídeos e processos interativos que evidenciem a diversidade de paisagens presentes no Brasil.

A depender da localidade onde a escola está inserida, o professor pode optar pela realização de atividade de campo como, por exemplo, em áreas com certo grau de preservação ambiental, tendo como objetivo que o aluno identifique as principais características físico-territoriais locais, como a composição das formações vegetais e do relevo. Esta possibilidade de contextualização das atividades didático-pedagógicas propostas em situações reais potencializam as vias de aprendizado pelos estudantes, na interconexão entre a teoria e a prática, os conceitos e a realidade proximal do ambiente escolar para além dos seus muros e salas de aula.

Silva (2007) aponta possibilidades de enriquecimento do ensino de Geografia, como a utilização de atividades que englobem ludicidade, como obras literárias, imagens, gibis, músicas e peças teatrais.

Em acréscimo a estas estratégias de instrumentação de ensino, o uso de quebra cabeças associados à cartografia, ou seja, a utilização de mapas quebra cabeças, é uma alternativa que pode representar incentivo aos estudos dos aspectos cartográficos, de forma a atrair a atenção do aluno e a tornar o processo instigante e interessante.

Para Guimarães e Odelfa (2014), através do uso do quebra cabeça, o aluno será incentivado a participar de atividades cartográficas com uso de uma brincadeira que envolva seu cotidiano e possa associá-lo com os acontecimentos globais.

No $8^{\circ}$ ano dos Anos Finais, observa-se que os objetos de conhecimento preveem o estudo do contexto mundial, com ênfase nos continentes, sobretudo o americano e o africano. Dessa forma, inicia-se, com maior propriedade, o estudo de contextos diferentes ao brasileiro, o que envolve uma gama de complexidades culturais, físicas, econômicas e sociais. Assim, o estabelecimento de paralelos entre a realidade brasileira, com conjunturas locais e regionais, com o contexto mundo é um dos pontos essenciais no ensino de Geografia para o referido ano.

O ensino dos objetos de conhecimento relacionados à "Distribuição da população mundial e deslocamentos populacionais" e "Diversidade e dinâmica da 
população mundial e local" (BRASIL, 2018, p.386) deve evidenciar os fluxos migratórios da população mundial durante os diferentes períodos históricos, as dinâmicas demográficas recentes e o contexto da América Latina em relação aos fluxos migratórios.

Para Vlach (2003), há total ligação do ensino de Geografia com o mundo, apesar de que o processo de ensino aprendizagem inicie pelo contexto local. Para a autora, "Como professores de Geografia, cabe-nos formar cidadãos não apenas na escala nacional, pois, nesse "mundo novo", é preciso preparar cidadãos para uma sociedade mundial." (VLACH, 2003, p. 2).

Também há a orientação de utilização dos objetos de conhecimento associado ao contexto geopolítico internacional "Corporações e organismos internacionais e do Brasil na ordem econômica mundial" (BRASIL, 2018, p.386), com habilidades notadamente atreladas ao contexto geopolítico, com foco nos continentes americano e africano, tais como os conflitos e tensões, com utilização dos conceitos de território, Estado e Nação, o papel dos Estados Unidos no cenário internacional e no continente americano, assim como suas relações com o Brasil e a China, além de enfatizar o papel dos BRICS (Brasil, Rússia, Índia, China e África do Sul) no cenário econômico e político atual.

Dessa maneira, o professor será desafiado a tratar de questões geopolíticas e, para isso, a utilização de quadrinhos, da charge e do cartum são recursos que possibilitam a diversificação das possibilidades de tratar tais temáticas. A utilização desses mecanismos em sala de aula vem se ampliando de forma considerável, inclusive em avaliações de processos seletivos. As possibilidades de utilização e as escalas são variadas, sejam elas locais, regionais, nacionais e mundiais.

Segundo Silva (2007), a charge e o cartum envolvem o uso de críticas sociais e políticas e apresentam grande potencialidade para tratar de questões como geopolítica e contextos internacionais e nacionais.

Um dos objetos de conhecimento para este ano do Ensino Fundamental está focado no estudo dos "diferentes contextos e os meios técnico e tecnológico na produção" (BRASIL, 2018, p.386), com ênfase no entendimento do papel 
desempenhado pelo desenvolvimento científico e tecnológico, os tipos de trabalho presentes na África e América, o capital chinês e americano- dinâmicas e movimentação no contexto mundial. Em concordância com tais proposições didáticopedagógicas, há a previsão, também, como objeto de conhecimento das "transformações do espaço na sociedade urbano-industrial na América Latina" (BRASIL, 2018, p.386), com o estudo dos recursos hídricos presentes na América Latina, as principais problemáticas das cidades latino-americanas relacionadas às condições de vida, processos segregacionistas e o contexto do trabalho.

Malyz (2007) considera que o ensino de Geografia deve ter como foco principal o entendimento, compreensão e interpretação dos seguintes fatores/processos: as diferentes paisagens, acontecimentos nos diferentes lugares, os conflitos territoriais, as contradições da sociedade globalizada e as questões socioambientais no contexto de uma sociedade de consumo.

No período atual, há necessidade de formação de uma sociedade com características inclusivas e que combata formas discriminatórias, estimulando-se a construção e fortalecimento de indivíduos solidários e capazes de conviver com os outros e suas diferenças.

A Geografia deve ser o campo do conhecimento que oferece possibilidades para reforço dos ideais referentes à democracia e cidadania (KAERCHER et. al., 2014; GUIMARÃES; ODELFA, 2014). Portanto, o ensino do objeto de conhecimento denominado "Identidades e interculturalidades regionais: Estados Unidos da América, América espanhola e portuguesa e África" (BRASIL, 2018, p.386) deve ser inspirado no entendimento das diferenças entre as identidades, do histórico de formação e dos aspectos culturais entre as sociedades presentes na América e África.

Os recursos imagéticos e contextuais, aliados ao uso de tecnologias de inovação e comunicação em sala de aula possibilitam uma exploração maior da correlação destas temáticas com os alunos (ALCARAZ; MONLLOR, 2016; MARKUSZEWSKA et. al., 2018). A requisição de processos cognitivos mais complexos, que demandam maior abstração faz com que a inovação, dialogada com a instrumentação de ensino e estratégias didático-pedagógica exija do professor um 
esforço de levar estas questões regionais e locais do contexto político e geográfico para a realidade de aprendizagem dos estudantes.

Portanto, o professor deve agir de forma a estimular e construir os ideais democráticos e éticos presentes na nossa atual sociedade no âmbito da Geografia Escolar por meio da instrumentação de ensino e estratégias didático-pedagógicas, para isso, é necessário que o professor concentre esforços na construção de uma prática didático-pedagógica em sala de aula inspirada nesses princípios, pois segundo Kaercher et. al (2014, p.6) "[...] as lembranças que temos dos nossos professores marcantes vem muito mais do que eles são/eram para nós do que os conteúdos que nos ensinaram."

Assim, a postura do profissional da educação em sala de aula é fundamental para a construção dos princípios ligados à formação da cidadania. A seriedade no empenho do seu trabalho, a elaboração de bons e variados planejamentos de aulas e avaliações e a construção de uma relação ética com os alunos podem representar um bom avanço na construção do processo de ensino e aprendizagem e de ideais democráticos.

Além disso, nesta fase dos Anos Finais do Ensino Fundamental para a Geografia Escolar, nota-se uma atenção aos objetos de conhecimento e habilidades com grande foco sobre a América Latina, um dos pontos essenciais para o aluno de $8^{\circ}$ ano. No entanto, com certa desvalorização do contexto africano. Nesse sentido, o estudo de diferentes aspectos do continente africano poderia ser mais explorado pelo BNCC, tendo em vista o histórico de formação da sociedade brasileira.

Para o $9^{\circ}$ ano dos Anos Finais da Geografia Escolar, de acordo com a BNCC, o destaque para os objetos de conhecimento intitulados: "Corporações e organismos internacionais", com consideração da atuação das organizações econômicas sobre a vida das populações, consumo, cultura e mobilidade; "Integração mundial e suas interpretações: globalização e mundialização" e "Transformações do espaço na sociedade urbano-industrial", em dialogia com a temática da inovação também para a questão da instrumentação de ensino e estratégias pedagógicas da Geografia Escolar (ALCARAZ; MONLLOR, 2016; MARKUSZEWSKA et. al., 2018). 
Os três objetos destacados possuem íntima ligação com o processo contraditório de globalização em seus múltiplos aspectos, sejam eles culturais, econômicos e políticos. Segundo Surmacz e Leme (2015, p.41) "[...] os conteúdos da disciplina trabalhados, em sala de aula, além de possibilitarem uma leitura de mundo, devem advertir o aluno que esse mundo contemporâneo globalizado é vivo, heterogêneo e cheio de contradições."

Neste ponto dos Anos Finais do Ensino Fundamental, com o avanço nos processos cognitivos de ensino e aprendizagem, destaca-se a necessidade da instrumentação de ensino e estratégias didático-pedagógicas acompanhar tais transformações e especificidades (FISCHER, 2016; HERRERO, 2004; IPARRAGUIRRE, 2013).

Segundo Vlach (2003), o professor de Geografia possui o importante papel na aprendizagem sobre o contexto mundial, de forma a favorecer o entendimento das principais diferenças entre as culturas e sociedades e os aspectos ligados à solidariedade e cidadania nas diferentes escalas do mundo globalizado.

A globalização, processo hegemônico e caracterizado pelas contradições, envolve uma gama de imaginários que podem levar ao professor riscos de tratá-la como um processo natural, com realidades pasteurizadas e virtuais. Além disso, há iminentes armadilhas que podem fazer com que o aluno entenda a globalização como um processo mágico de realidades tecnológicas e econômicas igualmente distribuídas pelo espaço geográfico, com desvalorização do contexto local, das particularidades e especificidades (CASTROGIOVANNI, 1996; VLACH, 2003).

Com isso, é necessário que o professor estabeleça uma linha de abordagem voltada para o entendimento dos processos contraditórios presentes no mundo globalizado, com a valorização das lógicas culturais, sociais e econômicas presentes na escala local. Para Guimarães e Odelfa (2014, p.71),

A Geografia é uma disciplina que possibilita entender as transformações no mundo de forma articulada, partindo do local para compreender o global e vice-versa. O conhecimento deve partir da realidade vivida do aluno, sendo resultado das ações do indivíduo e do social. 
A BNCC de Geografia para os Anos Finais do Ensino Fundamental também prevê o estudo dos "Intercâmbios históricos e culturais entre Europa, Ásia e Oceania", com ênfase nos aspectos físicos e culturais, nas regionalidades, fronteiras e emergência dos conflitos, além das desigualdades entre os países em relação aos aspectos populacionais, econômicos e demográficos.

Nesse aspecto, a abordagem sobre as perspectivas históricas e culturais deve permear o ensino desses objetos de conhecimento. Certamente, um dos pontos essenciais está na abordagem dos principais conflitos territoriais, étnicos e culturais presentes na Eurásia.

Para Vlach (2007), as condições sócio-ambientais se agravaram muito, em um quadro político-social violento e permeado por ações terroristas, que atingem indistintamente a população civil, em qualquer lugar do mundo.

Os objetos de conhecimento previstos para o $9^{\circ}$ ano são direcionados para ligações com os aspectos geopolíticos presentes na escala global, notadamente os dois eixos denominados "A hegemonia europeia na economia, na política e na cultura" e "A divisão do mundo em Ocidente e Oriente". Nesse caso, o primeiro objeto de conhecimento prevê como habilidade o entendimento da influência europeia sobre outras regiões e países. Já o segundo objeto, destaca a necessidade de entendimento do sistema colonial imposto pelas potências econômicas e bélicas europeias.

Vlach (2007) defende a mudança das práticas sociais dos professores de Geografia, para isso, aponta a necessidade de fortalecimento dos temas relacionados à Geografia Política e da geopolítica, com isso, construindo raciocínios geográficos vitais para a compreensão das problemáticas existentes no mundo.

Tal necessidade de fortalecimento das abordagens da Geografia Política e da geopolítica nas aulas de Geografia advém, entre outras questões, do fato de que a maior parte dos conflitos políticos, étnicos, sociais e culturais terem origem em disputas territoriais e envolvimento de diferentes Estados.

Portanto, os aspectos geopolíticos em torno dos países e continentes, especialmente no caso do ensino de Geografia dos $9^{\circ}$ anos, devem ser tratados com 
maior protagonismo. Ademais, as temáticas geopolíticas possuem um caráter multidisciplinar, o que possibilita ao professor um trabalho pautado na parceria com os outros campos do saber.

Dessa forma, a partir deste ano do Ensino Fundamental, é possível notar uma aproximação dos estudos geográficos com a contextualização dos fenômenos situacionais com os continentes europeu, asiático e da Oceania, prevendo o ensino pautado em análises críticas sobre diferentes contextos dos referidos recortes territoriais, inclusive com uso de atividades cartográficas direcionadas ao entendimento das dinâmicas econômicas, sociais, físicas e culturais presentes nos diferentes continentes.

Kaercher (2004) defende que o professor deve entender o caráter de criticidade não apenas pelo viés do denuncismo, ou seja, o de somente apontar as contradições e problemáticas presentes no atual quadro de mundo globalizado, e sim o de tentar estabelecer mecanismos de renovação do conhecimento e ensino geográfico. Portanto, para o autor, deve-se evitar a transformação da Geografia crítica em uma Geografia pastel de vento: "Geografia como Pastel de vento: há pouco a entender/refletir. Muito esquemática e simplista. Pastel de vento porque, visualmente, parece rico, saboroso, belo, mas após a primeira mordida fica aquela sensação de "eu esperava mais", "a Geografia pode mais". (KAERCHER, 2004, p. 58).

O fato do professor se intitular crítico não o faz superior e tampouco mais inovador e reflexivo quanto ao professor dito tradicional. Nesse aspecto, o professor deve estimular a participação dos alunos e estabelecer um processo de abertura a questionamentos e descobertas (KAERCHER, 2004). No entanto, o autor estabelece uma importante consideração:

Paradoxalmente, em nossas observações, ficou evidente que é cada vez mais rara a aula expositiva do professor. Ele quase não professa, quase não assume mais o protagonismo da aula. Tem substituído a sua organização de idéias pela leitura não raro de forma individual e sem explicações para o grupo de alunos - de textos do livro didático e pela posterior resposta de algum questionário. (KAERCHER, 2004, p.55). 
Dessa forma, o professor não deve renunciar totalmente do seu importante papel de condutor e protagonista das aulas, entretanto, de maneira a não transformar o aluno ao que Kaercher (2004) denomina de receptáculo. O caráter de protagonismo do professor também é destacado por Surmacz e Leme (2015), pois é o mediador entre o aluno e os conteúdos geográficos, sendo responsável pela seleção do caminho metodológico para se alcançar o entendimento dos fenômenos geográficos.

O professor deve assumir o seu papel na qualidade de profissional reflexivoativo e qualificar-se como profissional comunicativo-transformativo (KENNEDY, 2015). Nesse sentido, o professor é um sujeito ativo do processo de ensino e aprendizagem e deve utilizar do seu potencial dialógico e ações educativas ancoradas na construção reflexiva de saberes com o intuito de formar cidadãos críticos e capazes de contribuírem para a transformação da sociedade onde vivem.

\section{CONSIDERAÇÕES FINAIS}

A discussão referente ao processo da instrumentação em Geografia revela-se como uma temática urgente e fundamental ao considerar a necessidade de efetivação de um ensino pautado na construção de raciocínios geográficos sob o viés da criticidade, tendo em vista o contexto de rápidas e intensas transformações pela qual o mundo passa.

O ensino de Geografia deve acompanhar as constantes mudanças econômicas, sociais, culturais e ambientais em curso. Como se trata de um campo científico com foco na relação entre a sociedade e a natureza, o professor de Geografia pode contribuir de maneira significativa para o entendimento e resolução das principais problemáticas da sociedade atual, tendo em vista o seu importante papel como formador de raciocínios geográficos.

Pela análise da BNCC, pode-se destacar dez pontos em comum entre os diferentes objetos de conhecimento e habilidades previstos para anos considerados, tais como: 1) relevância das categorias analíticas da Geografia para o entendimento dos processos e fenômenos geográficos; 2) o potencial da cartografia como 
ferramenta e recurso indispensável à Geografia; 3) a necessidade de partir do contexto local, como valorização do conhecimento prévio dos alunos; 4) a interface e complementaridade entre a Geografia Física e Humana; 5) o protagonismo do ser humano como transformador das paisagens e no agravamento de problemáticas socioambientais; 6) a formação de cidadãos críticos e com capacidade de reconhecer e aceitar diferenças entre os sujeitos e sociedades; 7) a proposição de soluções para problemáticas presentes em diferentes contextos; 8) a centralidade do debate sobre as questões ambientais, tais como as alterações climáticas, o desmatamento e a poluição dos recursos hídricos; 9) a relevância da Geopolítica no processo de ensino e aprendizagem e 10) a valorização e consideração dos contextos históricos, sociais e culturais de comunidades historicamente marginalizadas, como os indígenas, negros e minorias étnicas.

Pelo caráter recente das modificações da BNCC, é possível avaliar que ainda é prematuro destacar quais os seus reais impactos no ensino de Geografia, assim como sua real aplicabilidade em sala de aula, sobretudo em decorrência das dificuldades dos parâmetros curriculares realmente chegarem ao professor, já que este é um dos grandes desafios, pois muitos profissionais da educação acabam ignorando as proposições dos parâmetros curriculares.

Especialmente se considerarmos a BNCC como referencial de elaboração de currículos, e não o currículo propriamente dito, em diferentes redes de ensino, já que seu papel é o de fornecer as orientações da aprendizagem essencial da Educação Básica, cabendo aos técnicos e especialistas, juntamente com os professores e gestores e demais atores da construção curricular construírem seus documentos de norteamento das aprendizagens em suas redes de ensino.

Dessa forma, surgem outras questões possíveis de serem exploradas em trabalhos futuros, como exemplo, as propostas de livros didáticos que chegarão com o Plano Nacional do Livro Didático (PNLD) e a BNCC e a carência da formação continuada dos profissionais da educação acerca das novas diretrizes da base nacional para a construção curricular. No entanto, ressalta-se a fundamental importância do estímulo ao debate sobre a nova BNCC entre os professores dentro 
dos muros da escola, já que sem isso, muitos nem mesmo tem contato ou conhecimento dos novos parâmetros curriculares.

É vital destacar que a BNCC envolve um conjunto de análise e posicionamentos que possuem divergências entre a concordância de seu papel de base curricular nacional e críticas em relação ao contexto econômico, político e social global dos quais a mesma faz parte. O fomento ao intercâmbio entre educação e mundo do trabalho faz parte da BNCC, e de demais orientações educacionais contemporâneas, envolvendo, também competências socioemocionais, uso das Tecnologias Digitais de Informação e Comunicação (TIDCS), e que são e ainda serão palco de amplas discussões e possibilidades de aprofundamento nos próximos anos.

Apesar disso, a proposta do artigo foi fornecer pistas em torno da instrumentação do ensino de Geografia a partir da BNCC para Ensino Fundamental, nos quatro anos finais destinados a inserção dos componentes curriculares específicos, dos quais faz parte a Geografia. Ao longo da análise apresentada, observa-se, de igual modo, que a proposição das habilidades específicas de Geografia para os Anos Finais do Ensino Fundamental, bem como seus respectivos objetos de conhecimento, trazem consigo tanto o desafio como possibilidades ao professor de Geografia, na busca pelo desenvolvimento de formas de instrumentação de ensino, na aproximação e intersecção entre teoria e prática para temáticas como Geopolítica, estrutura interna da Terra, regionalizações brasileiras, dentre outras temas tão ricos quanto profícuos à instrumentação de ensino de Geografia.

\section{REFERÊNCIAS BIBLIOGRÁFICAS}

ADURIZ-BRAVO, et. al. https://www.oei.es/historico/divulgacioncientifica/?Ensenanza-de-lasciencias-en-la. In: Ibero America Divulga. Disponível em: $<$ https://www.oei.es/historico/divulgacioncientifica/?Ensenanza-de-las-ciencias-en-la> Acesso em: 25.05.2019.

ALCARAZ, Rafael Sebastiá; MONLLOR, Emília María. [Org.] La investigación e innovación em la enseñanza de la geografia. Alicante: Publicaciones de la Universidad de Alicante, 2016. 
ANTONIO FILHO, Fadel David. Geografia Prática: Instrumentação para o Ensino de Geografia - II (Mapa Furado e Bússola Seca) In: Conteúdos e Didática de Geografia. 1ed.São Paulo (SP): Cultura Acadêmica - Universidade Virtual do Estado de São Paulo, 2012, v. 9.

BRASIL. Base Nacional Comum Curricular. Brasília: MEC/Secretaria de Educação Básica, 2018.

CALLAI, Helena Copetti. Aprendendo a ler o mundo: a Geografia nos anos iniciais do Ensino Fundamental. In: Cadernos do CEDES, Campinas-SP, v. 25, n.66, p. 227-247, 2005. Disponível em: < http://www.scielo.br/pdf/ccedes/v25n66/a06v2566.pdf> Acesso em 25.05.2019.

O ensino de geografia: Recortes espaciais para análise. In: CASTROGIOVANNI, Antonio Carlos et. al. Geografia em sala de aula: prática e reflexões. 5 ed. Porto Alegre: UFRGS, 2010. p.57-63.

CASTELLAR, Sonia. Educação Geográfica: A psicogenética e o conhecimento escolar. Cad. Cedes, Campinas vol. 25 n.66 pg. 209-225 maio/agosto 2005. Disponível em: <http://www.scielo.br/pdf/\%0D/ccedes/v25n66/a05v2566.pdf > : Acesso: 15.02.2019.

CASTROGIOVANNI, Antonio Carlos. E agora, como fica o ensino da Geografia com a globalização? In: Boletim Gaúcho de Geografia, 21: 95-97, ago., 1996. Disponível em: <https://seer.ufrgs.br/bgg/article/view/38634> Acesso em: 30.05.2019.

CAVALCANTI, Lana de Sousa. Ensinar Geografia para a autonomia do pensamento: o desafio de superar dualismos pelo pensamento teórico crítico. In: Anais do IX Encontro Nacional da ANPEGE. Goiânia: Universidade Federal de Goiás. Goiânia, 2011. A geografia e a realidade escolar contemporânea: avanços, caminhos, alternativas. In: I Seminário Nacional: Currículo em Movimento Perspectivas Atuais, 2010, Belo Horizonte. Anais do I Seminário nacional: Currículo em Movimento: perspectivas atuais, 2010. p. 1-15.

EADY, Michelle J.; LOCKYER, Lori. Tools for learning: technology and teaching strategies. In: Deputy Vice-Chancellor (Academic) - Papers. p. 1-23, 2013. Disponívelem < https://ro.uow.edu.au/cgi/viewcontent.cgi?referer=https://www.google.com/\&http sredir $=1 \&$ article $=1413 \&$ context $=$ asdpapers $>$ : Acesso em: 14.06.2019.

FISCHER, Kurt M. Mind, Brain, and Education: Building a Scientific Groundwork for Learning and Teaching. In: Building a Scientific Groundwork. Harvard University Graduate School of Education, Vol. 3 No 1 p. 3-16, 2016.Disponível em:<https://www.gse.harvard.edu/ ddl/articlesCopy/FischerGroundwork.MBE2009.3.1.pdf $>$ Acess oem 30.06.2019.

GEIGER, Pedro Pinchas. Regionalização. Revista Brasileira de Geografia. Rio de Janeiro. v. 31, no 1. 1969. p. 5-25. 
GUIMARÃES, Rosiane Correa, ODELFA, Rosa. Ensinando Geografia de forma lúdica através do mapa quebra-cabeça. Revista Caminhos de Geografia, Uberlândia, v.15, n.49, p.70-79, 2014. <http://www.seer.ufu.br/index.php/caminhosdegeografia/article/view/23159>. Acesso em: 30.06.2019.

HERRERO, Isidoro Moreno. La utilización de medios y recursos didácticos em el aula. In: Revista Del Departamento de Didáctica y Organización Escolar Facultad de Educación, Universidad Complutense de Madrid. p. 1-14, 2004. Disponível em: < https://webs.ucm.es/info/doe/profe/isidro/merecur.pdf> Acesso em 25.06.2019.

IPARRAGUIRRE, Julia Nohemí. El material educativo em el proceso de enseñanza aprendizaje em la educación inicial. In: Perspectivas Em Primera Infancia.Vol. 2 No 1, 2013, p. 1-6. Disponível em < http://revistas.unitru.edu.pe/index.php/PET/article/view/530/502>: Acesso 20.05.2019.

KAERCHER, Nestor André. et al. Espaços de controle na Geografia escolar. In: XIII Coloquio Internacional de Geocrítica: El control del espacio y los espacios de control, Barcelona, 5-10 mayo de 2014. Disponível em: <http://www.ub.edu/geocrit/coloquio2014/Castrogiovanni\%20Tonini\%20Kaerccher\%20Costella.pd f> Acesso em 25.05.2019.

Quando a Geografia crítica pode ser um pastel de vento. Mercator, Fortaleza, v. 3, n. 6, 2004. Disponível em: <http://www.mercator.ufc.br/mercator/article/view/126> Acesso em 20.05.2019.

KENNEDY, Francisco. O professor de geografia na perspectiva do profissional comunicativo-transformativo. Revista de Ensino de Geografia, v. 6, p. 48-61, 2015. Disponível em: <http://www.revistaensinogeografia.ig.ufu.br/N11/Art7-Revista-Ensino-Geografiav6-n11-Santos.pdf $>$ Acesso em 30.06.2019.

MALYZ, Sandra T. Estágio em parceria universidade-educação básica. In: PASSINI, Elza Yasuko. Práticas de ensino de geografia e estágio supervisionado. São Paulo, Contexto, p. 16-25, 2007.

MANSILLA, Veronica Boix; JACKSON, Anthony. Educating for Global Competence: Learning Redefined for an Interconnected World. In: JACOBS, H. (org.), Mastering Global Literacy, Contemporary Perspectives. New York: Solution Tree, 2013, p.5-27. Disponível em < http://www.pz.harvard.edu/sites/default/files/Educating\%20for\%20Global\%20Competence\%20S hort\%20HHJ.pdf>. Acessoem: 21.05.2018.

MARKUSZEWSKA, Iwonaet. etal. New ways to learn geography - challenges of the 21st century. In: Quaestiones Geographicae 37(1), $2018 . \quad$ Disponível em<file:///C:/Users/Acer/Downloads/[20816383\%20-

\%20Quaestiones\%20Geographicael\%20New\%20ways\%20to\%20learn\%20geography\%20\%E2\%80\% 93\%20challenges\%20of\%20the\%2021st\%20century.pdf>Acessoem: 20.07.2019. 
MARTINS, Rosa Elisabete MilitzWypyczynski. Os desafios do processo formativo do professor de geografia. Tese de Doutorado em Geografia pelo Programa de PósGraduação em Geografia da Universidade Federal do Rio Grande do Sul. Porto Alegre/RS: UFRS, 2010.

McGUIRE, James; TUCHANSKA, Barbara. Da ciência descontextualizada à ciência no contexto social e histórico. In: Revista Brasileira de História da Ciência, Rio de Janeiro, v. 6, n. 2, p. 151-182 jul | dez 2013. Disponível em: <file:///C:/Users/Acer/Downloads/sbhc\%202013 2\%20McGUIRE TUCHANSKA.pdf> Acesso em: 20.02.2019

PAZINI, Dulce Leia Garcia. Geoprocessamento no ensino fundamental: utilizando o SIG no ensino de geografia para alunos de $5^{a}$ a $8^{a}$ série. In: Anais XII Simpósio de Sensoriamento Remoto, Goiânia, Brasil, p. 1329-1336, 2005. Disponível em: < http://files.profricardoferreira.webnode.com/2000000202289a2384c/1.pazini geop ensino geog.p $\underline{\mathrm{df}}>$ : Acesso em: 01.05.2019.

PÉREZ, Carmen Lúcia Vidal. Ler o espaço para Compreender o Mundo: a função alfabetizadora da geografia. In: Revista Tamoios (Impresso), v. 2, p. 17-24, 2005. Disponível em: <https://www.e-publicacoes.uerj.br/index.php/tamoios/article/view/646 > : Acesso: 01.04.2019.

PONTUSCHKA, Nídia Nacib; PAGANELLI, Tomoko Lyda; CACETE Núria Hanglei. Para ensinar e aprender Geografia. Coleção docência em formação. Série Ensino Fundamental. 3 ed. São Paulo: Cortez, 2009.

PUNTEL, Geovane Aparecida. A Paisagem no ensino da Geografia. Ágora, SantaCruz do Sul, vol. 13, n.1, p.283-298, jan./jun., 2007. Disponível em:<http://online.unisc.br/seer/index.php/agora/article/view/130>: Acesso em: 28.04.2019.

SANTOS, Milton; SILVEIRA, María Laura. As diferenciações no território. In: O Brasil: Território e sociedade no início do século XXI. 13 ${ }^{a}$ Ed. São Paulo. Record, 2010, p.259277.

SILVA, Eunice Isaias. Charge, cartum e quadrinhos: linguagem alternativa no ensino de geografia. In: Revista Solta a Voz. Vol. 18, $\mathrm{n}^{\circ}$ 1. p. 41-49. 2007. Disponível em: <https://www.revistas.ufg.br/sv/article/view/2512> Acesso em: 29.04.2019.

SILVA, Vládia; MUNIZ, Alexsandra Maria Vieira. A geografia escolar e os recursos didáticos: o uso das maquetes no ensino aprendizagem da geografia. Geosaberes, Fortaleza, v. 3, n. 5, p. 62-68, jan./ jun. 2012. Disponível em: < https://www.redalyc.org/pdf/5528/552856435008.pdf > : Acesso em: 04.05.2019.

SURMACZ, Elaine Cristina Soares; LEME, Rosana Cristina Biral. O professor é, a priori, responsável pela motivação do aluno em sala de aula. In: Revista de Ensino de Geografia, Uberlândia, v.6, n.11, p.37-64, 2015. Disponível em: <http://www.revistaensinogeografia.ig.ufu.br/N11/ResumoArt3-v6n11-Surmacz-Leme.php > : Acesso em: 20.05.2019 
VLACH, Vânia. O papel do ensino de Geografia na compreensão de problemas do mundo atual. In: IX Colóquio Internacional de Geocrítica: los problemas del mundo actual. Soluciones y alternativas desde la geografia y las ciências sociales, Porto Alegre, 28 de mayo-1de junio, 2007. Disponível em: <http://www.ub.edu/geocrit/9porto/vlach.htm> Acesso em: 20.05.2019.

Ensino de Geografia no início do século XXI: Desafios e perspectivas. Mérida (México): Anais do Encuentro de Geógrafos de América Latina, 2003. Disponível em: $<$ http://observatoriogeograficoamericalatina.org.mx/egal9/Teoriaymetodo/Teoricos/04.pdf $>$

Acesso em: 18.06.2019.

Notas

1 "De uma perspectiva didática, poderíamos dizer que recurso é uma maneira de agir, ou melhor, a capacidade de decidir sobre o tipo de estratégias que serão usadas nos processos de ensino."

2 "É, portanto, uma característica inerente à capacidade de ação das pessoas. A mídia didática poderíamos defini-las como o instrumento que usamos para a construção do conhecimento; e, finalmente, os materiais didáticos seriam os produtos projetados para ajudar nos processos de aprendizagem"

3 "Nesse sentido, usaremos os meios e materiais didáticos como instrumento a serviço de estratégias metodológicas. Essa idéia já foi apontada quando se fala em uso de recursos do ponto de vista da teoria interpretativa do currículo. Assim, sob essa perspectiva, qualquer meio faria parte dos componentes metodológicos considerados na categoria de material curricular, uma vez que se torna a ferramenta para auxiliar na construção do conhecimento. Os meios tecnológicos, acima de tudo, como suportes dos processos de comunicação e representação simbólica tornam-se elementos mediadores das situações de ensino e dos processos de aprendizagem."

4 "A aprendizagem experiencial é uma abstração que não oferece métodos e modelos exatos para ensinar alunos do que antes. $O$ instrutor é necessário para selecionar métodos de ensino e aprendizagem viáveis e razoáveis em relação à matéria e ao núcleo de um módulo de estudo. Na prática, os resultados de aprendizagem elegíveis e os conteúdos do curso estão direcionados a seleção dos métodos de estudo."

5 "Melhorar os fundamentos da pesquisa em práticas e políticas educacionais requer a construção de uma infraestrutura mais forte para criar uma melhor pesquisa educacional. Essa pesquisa precisa ser não apenas cientificamente sólida, mas também relacionada à maneira como o ensino e a aprendizagem acontecem em importantes contextos educacionais, como escolas, campos de jogos, televisão e internet. Três mudanças que contribuirão para uma infraestrutura mais forte são: (a) a criação de escolas de pesquisa para promover pesquisas que se conectem à prática e à política; (b) ao estabelecimento de bancos de dados úteis sobre aprendizado e desenvolvimento; e (c) à invenção de uma nova classe de educador especializado em tradução entre pesquisa e prática e/ou em materiais e atividades educacionais de engenharia com base em pesquisa."

6 "Uma instituição escolar significativa, baseada em modelos, que intervém na transformação, que é criada com o auxílio da epistemologia e da história da ciência, e que resultados são fundamentais para tomar decisões informadas na vida cotidiana." 